\title{
An essential role for the Id1/PI3K/Akt/NFkB/survivin signalling pathway in promoting the proliferation of endothelial progenitor cells in vitro
}

\author{
Wei Li $\cdot$ Hang Wang $\cdot$ Chun-yan Kuang • \\ Jin-kun Zhu $\cdot$ Yang Yu - Zhe-xue Qin · \\ Jie Liu $\cdot$ Lan Huang
}

Received: 3 August 2011/Accepted: 23 November 2011/Published online: 3 December 2011

(C) The Author(s) 2011. This article is published with open access at Springerlink.com

\begin{abstract}
The enhancement of re-endothelialisation is a critical therapeutic option for repairing injured blood vessels. Endothelial progenitor cells (EPCs) are the major source of cells that participate in endothelium repair and contribute to re-endothelialisation by reducing neointima formation after vascular injury. The over-expression of the inhibitor of differentiation or DNA binding 1 (Id1) significantly improved EPC proliferation. This study aimed to investigate the effects of Id1 on the phosphatidylinositol-3kinase (PI3K)/Akt/nuclear factor kappa B (NF $\kappa \mathrm{B}) /$ survivin signalling pathway and its significance in promoting EPC proliferation in vitro. Spleen-derived EPCs were cultured as previously described. Id1 was presented at low levels in EPCs, and was rapidly up-regulated by stimulation with vascular endothelial growth factor. We demonstrated that transient transfection of Id1 into EPCs activated the PI3K/ $\mathrm{Akt} / \mathrm{NF} \kappa \mathrm{B} /$ survivin signalling pathway and promoted EPC proliferation. The proliferation of EPCs was extensively inhibited by silencing of endogenous Id1, and knockdown of Id 1 expression led to suppression of $\mathrm{PI} 3 \mathrm{~K} / \mathrm{Akt} / \mathrm{NF} \kappa \mathrm{B} /$ survivin signalling pathway in EPCs. In addition, blockade by the PI3K-specific inhibitor LY294002, Akt inhibitor, the $\mathrm{NF} \kappa \mathrm{B}$ inhibitor BAY 11-7082, the survivin inhibitor Curcumin, or the survivin inhibitor YM155 reduced the effects of Id1 transfection. These results suggest that the Id1/PI3K/ $\mathrm{Akt} / \mathrm{NF} \kappa \mathrm{B} /$ survivin signalling pathway plays a critical role in EPC proliferation. The Id1/PI3K/Akt/NF $\kappa \mathrm{B} /$ survivin
\end{abstract}

W. Li · H. Wang · C. Kuang · J. Zhu · Y. Yu - Z. Qin · J. Liu

L. Huang $(\bowtie)$

Institute of Cardiovascular Diseases of PLA, Xinqiao Hospital, Third Military Medical University, Chongqing 400037,

People's Republic of China

e-mail: huanglans260@163.com signalling pathway may represent a novel therapeutic target in the prevention of restenosis after vascular injury.

Keywords Inhibitor of differentiation or DNA binding $1 \cdot$ Endothelial progenitor cells $\cdot$ Proliferation

\section{Introduction}

Atherosclerosis is the pathological basis of cardiovascular disease, and the progression from the onset of atherosclerosis to cardiovascular disease can take decades [1]. Endothelial damage is a major contributing factor to atherosclerosis and post-angioplasty restenosis [2, 3]. The enhancement of re-endothelialisation is a critical therapeutic option for repairing injured blood vessels $[4,5]$. The number and function of circulating endothelial progenitor cells (EPCs) are inversely correlated with risk factors for coronary artery disease and are predictive of the occurrence of cardiovascular events and death [6, 7]. EPCs can home to sites of tissue injury, differentiate into mature ECs, and participate in re-endothelialisation after vascular injury [8-11]. Increasing evidence suggests that the circulation of EPCs may be an endogenous repair mechanism for maintaining the integrity of the endothelial monolayer by replacing denuded segments of the artery [12-14]. The migration and proliferation of EPCs are the key mechanisms of vascular development [15]. These mechanisms are regulated by various processes and signals. However, the regulatory mechanisms of the biological properties of EPCs remain unclear. Recent studies demonstrated that tumour-induced expression of inhibitor of differentiation or DNA binding 1 (Id1) in EPCs and conditional Id1 suppression impaired the mobilisation of EPCs [16]. 
Id1 is an important subfamily member of the helixloop-helix (HLH) proteins. Increased Id1 expression has been implicated in regulating the growth, proliferation, migration, and differentiation of cells [17]. Moreover, Id1 has been demonstrated to promote the proliferation and survival of bone marrow- and spleen-derived EPCs [18, 19]. However, the signalling mechanisms responsible for Id1-mediated EPC functions have not been addressed. It has been reported that Id1 is possibly linked to the phosphatidylinositol-3-kinase (PI3K)/Akt, PI3K/Akt/nuclear factor kappa $\mathrm{B}(\mathrm{NF} \kappa \mathrm{B})$, and $\mathrm{NF} \kappa \mathrm{B} /$ survivin pathways in many types of cancer cells [20-23]. Several studies have demonstrated that PI3K is necessary for Id1-mediated cell proliferation and survival $[20,22]$. One of the crucial downstream targets of PI3K is the serine/threonine kinase Akt, which is recruited to the membrane by direct binding of its pleckstrin homology domain to the PI3K-produced phosphatidylinositol 3,4,5-trisphosphate. Activated Akt can phosphorylate a number of proteins including glycogen synthase kinase-3 $\beta$ (GSK-3 $\beta$ ), 6-phosphofructo-2-kinase, and $\mathrm{I} \kappa \mathrm{B}$. The phosphorylation of $\mathrm{I} \kappa \mathrm{B}$ frees $\mathrm{NF} \kappa \mathrm{B}$ and allows it to translocate to the nucleus to bind and subsequently activate target genes. Survivin, a prominent anticancer target, is ubiquitously expressed in a plethora of cancers. Pertaining to recent studies, the modulation of survivin is critically regulated by its interaction with prominent cell-signalling pathways such as the PI3K/Akt, mTOR, ERK, and $\mathrm{NF} \kappa \mathrm{B}$ pathways $[22,24,25]$. A recent study indicated that the expression of survivin is under the control of $\mathrm{NF} \kappa \mathrm{B}$ [22]. However, the mechanism responsible for Id $1 / \mathrm{PI} 3 \mathrm{~K} / \mathrm{Akt} / \mathrm{NF} \kappa \mathrm{B} /$ survivin pathway activation in EPCs is largely unknown.

In this study, we hypothesised that Id1 is linked to the proliferation of EPCs via the regulation of the PI3K/Akt/ $\mathrm{NF} \kappa \mathrm{B} /$ survivin pathway. Our in vitro data demonstrated that Id1 up-regulated survivin via a PI3K/Akt/NF $\kappa \mathrm{B}$ dependent mechanism, contributing to the proliferation of EPCs.

\section{Materials and methods}

Study approval

All procedures were performed in accordance with the guidelines of the Animal Research Committee of the Third Military Medical University, Chongqing, China.

Animals

Sprague-Dawley rats (1-2 months old, 180-200 g weight) were obtained from the Experimental Animal Centre of Third Military Medical University.
Isolation and characterisation of EPCs

The culture and characterisation of EPCs were performed according to previous methods used by our research group [26]. Briefly, total spleen-derived mononuclear cells were isolated by density gradient centrifugation (Lymphoprep 1.083 , Tianjin, China) at $400 \times g$ for $20 \mathrm{~min}$. After purification using three washing steps, the cells were plated on gelatine-coated cell culture flasks and re-suspended in lowglucose Dulbecco's modified Eagle's medium (DMEM-L) supplemented with $10 \%$ foetal calf serum (FCS) and $10 \mathrm{ng} /$ $\mathrm{ml}$ vascular endothelial growth factor (VEGF). The cells were incubated at $37^{\circ} \mathrm{C}$ under an atmosphere of $5 \% \mathrm{CO}_{2}$. Twenty-four hours later, non-adherent cells were transferred to a new flask to remove adherent hematopoietic cells and mature ECs. Another $48 \mathrm{~h}$ later, non-attached cells were removed, and the adherent cells were cultured continuously. Only adherent cells were used in further experiments. The medium was refreshed every 3 days. For characterisation, the cells were incubated with Dil-Ac-LDL $(10 \mathrm{mg} / \mathrm{ml})$ for $4 \mathrm{~h}$, fixed with $4 \%$ paraformaldehyde and then incubated with FITC-labelled lectin (UEA-1, $10 \mathrm{mg} / \mathrm{ml}$ ) for $1 \mathrm{~h}$. Finally, the cells were incubated with 4',6-diamidino-2phenylindole (DAPI, $1 \mu \mathrm{g} / \mathrm{ml}$ ) for $5 \mathrm{~min}$. Triple-stained cells positive for Dil-Ac-LDL, lectin and DAPI were identified as EPCs. Additionally, flow cytometric cell sorting (FACS) analysis was performed using antibodies against rat CD133, CD34, CD45, VEGFR-2, and the corresponding isotype control antibodies (Bios, Beijing, China).

\section{Reagents}

The anti-Id1 antibody was purchased from Abcam; anti-pPI3K, anti-PI3K, anti-p-Akt, anti-Akt, anti-p-I $\kappa \mathrm{B}$, antisurvivin, and anti-NF $\kappa \mathrm{B} / \mathrm{p} 65$ antibodies were obtained from Cell Signaling Technology. FCS was obtained from HyClone. Medium and supplements were purchased from Gibco BRL. LY294002, BAY 11-7082, Akt inhibitor, and Curcumin were obtained from Santa Cruz Biotechnology.

Recombinant adenoviral vectors expressing Id1

An adenovirus (Ad) vector expressing Id 1 or $\mathrm{CCN} 1$ and an Ad-encoding green fluorescent protein (GFP; Ad-GFP) were used as controls and were previously created by our group [27]. The EPCs were transfected with Ad-Id1, Ad-CCN1, or Ad-GFP for $48 \mathrm{~h}$ and used in the experiments.

Small interfering RNA-mediated silencing of Id1 expression

Transient silencing of Id1 was accomplished by transfection with small interfering RNAs (si-Id1). The selected 
siRNA duplex sequences specifically targeted rat Id1 (rId1, GenBank accession number NM_012797), and showed no homology to any other sequences by a blast search. The si-Id1 target site is $5^{\prime}$-ttgtcgcgaccgccggaggcc-3' from 380 to $400 \mathrm{bp}$. A non-silencing control (si-CON) sequence was designed according to the sequence of a negative control. Transfection of si-Id1 was carried out using Lipofectamine 2000 reagent with a molar ratio between DNA and lipid of about 1:3. Forty-eight hours after transfection, cells were collected and used for functional assays.

\section{Western blot analysis}

Proteins from cell lysates were measured using the Bradford method. Equal amounts of the soluble fractions were separated by a $10-15 \%$ SDS-PAGE gel and electrophoretically transferred onto a polyvinylidene difluoride membrane. The membranes were blocked with 5\% non-fat milk. The membranes were allowed to react with a primary antibody, and the detection of specific proteins was performed by enhanced chemiluminescence following the manufacturer's instructions. The densitometric signals were quantified by Quantity One.

\section{Enzyme-linked immunospecific assay (ELISA)}

Protein levels of VEGF in the cell supernatants were determined by ELISA kit (R\&D Systems), according to the manufacturer's instructions. Samples were measured in triplicate and were properly diluted to ensure that measured values were within the concentration range of the standard curve.

\section{Cell proliferation assay}

The EPCs were trypsinised from the cultures and placed into fibronectin-coated 96-well plates $\left(2 \times 10^{6} \mathrm{cells} / \mathrm{ml}\right)$. Cell proliferation was measured by the 3-(4, 5-dimethylthiazol-2yl)-5(3-carboxymethoxyphenyl)-2-(4-sulfopheny)-2H-tetrazolium (MTS) assay according to the manufacturer's protocol. Before reading the optical density $(490 \mathrm{~nm}), 20 \mu \mathrm{l}$ of MTS solution was added to each well. All groups of experiments were performed in triplicate.

\section{Statistical analysis}

Data from at least three independent experiments are expressed as the mean \pm SD. SPSS 18.0 software was used for statistical analysis. Groups of data were compared with ANOVA followed by a Tukey's multiple comparison tests. $P$ values $<0.05$ were taken to be statistically significant.

\section{Results}

Characterisation of spleen-derived EPCs

After 5-7 days in culture, the attached cells were analysed using immunofluorescence and FACS. Immunocytochemistry staining demonstrated that the majority of the cells $(>90 \%)$ stained positively for Dil-Ac-LDL, lectin, and DAPI (Fig. 1a) and expressed endothelial/stem cell markers including CD133, CD34, and VEGFR-2 but not CD45 (Fig. 1b).

Id1 expression is up-regulated in EPCs in the presence of VEGF

We then investigated the expression of Id 1 in primary EPCs. As shown in Fig. 2a, Id1 was present at fairly low levels in quiescent EPCs, but was rapidly up-regulated upon stimulation with serum and VEGF. And, the proliferation of EPCs was significantly accelerated after stimulation with VEGF compared with control group (Fig. 2b). Given the significant correlation between Id1 and VEGF, we then investigated whether there is an interaction between Id1 and VEGF in EPCs. In this study, we constructed recombinant Ad, Ad-Id1, and transduced it into EPCs to examine the effect on VEGF at protein levels. By ELISA, there was a significant increase in VEGF protein secretion in Id1 transfectants when compared with the control (Fig. 2c). These results indicated an important relationship between Id1 and VEGF in EPCs.

Id1 is involved in the effect of the PI3K/Akt/NF $\kappa \mathrm{B} /$ survivin pathway on EPC proliferation

Id1 has an important role in the proliferation, differentiation, and migration of cells. Id1 activates the PI3K/Akt, $\mathrm{PI} 3 \mathrm{~K} / \mathrm{Akt} / \mathrm{NF} \kappa \mathrm{B}$, and $\mathrm{NF} \kappa \mathrm{B} /$ survivin signalling pathways, and protects cancer cells from apoptosis in vitro [20-22]. We previously observed that Id1 promoted EPC proliferation [18]. To clarify whether there is any association between Id 1 and PI3K/Akt/NF $\kappa \mathrm{B} /$ survivin signalling in the regulation of EPC proliferation, Ad-Id1 or Ad-GFP was transiently transfected into EPCs. As shown in Fig. 3a, there was increased Id1, p-PI3K, p-Akt, p-I $\kappa \mathrm{B}$, and survivin expression and increased nuclear translocation of $\mathrm{NF} \kappa \mathrm{B} / \mathrm{p} 65$ in EPCs transfected with Ad-Id1. EPCs transfected with Ad-Id1 and Ad-GFP were subsequently subjected to the MTS assay separately to examine their proliferation. The proliferation of EPCs transfected with Ad-Id1 was enhanced to about $200 \%$ compared with that of Ad-GFP transfected EPCs $(P<0.05)$ (Fig. 3c).

Although the over-expression of exogenous Id 1 directly enhanced EPC proliferation, the role of endogenous Id1 was not fully elucidated. Because the basal expression of 
Fig. 1 The isolation and characterisation of EPCs. a EPCs stained positive for DilAc-LDL, lectin, and DAPI (magnification $\times 400$ ). b FACS analysis of primary EPCs cultured for 5-7 days in lowglucose DMEM supplemented with $10 \%$ FCS. Cells labelled with fluorescent antibodies CD133, CD34, CD45, and VEGFR-2 are shown in the areas to the right in each box. The left area in each box represents the corresponding negative control labelling, and the line denotes a positive gate. The numbers are the percentage of positive cells
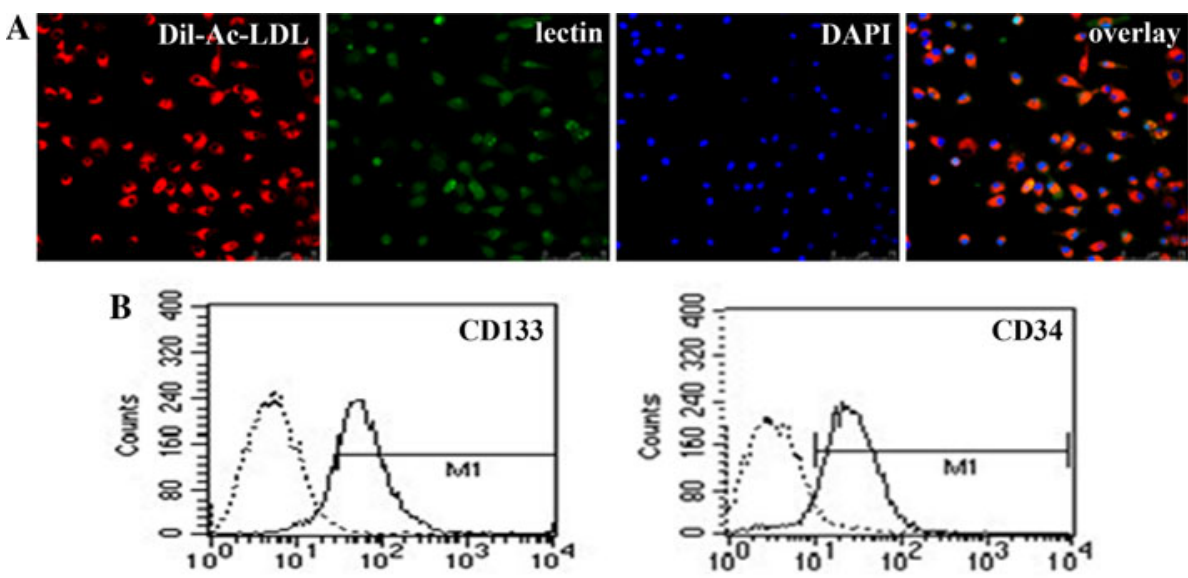

DL1: 0.81\% 日LM1: $92.51 \%$
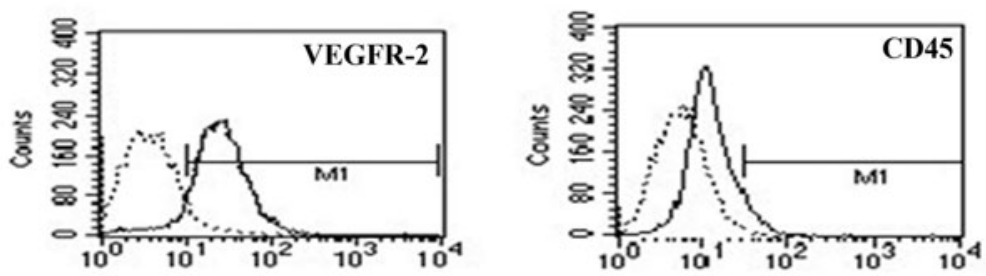

母LM1: $0.79 \%$ 日LM1: $90.81 \%$

LM1: 0.29\% 日 LM1: $5.93 \%$
A

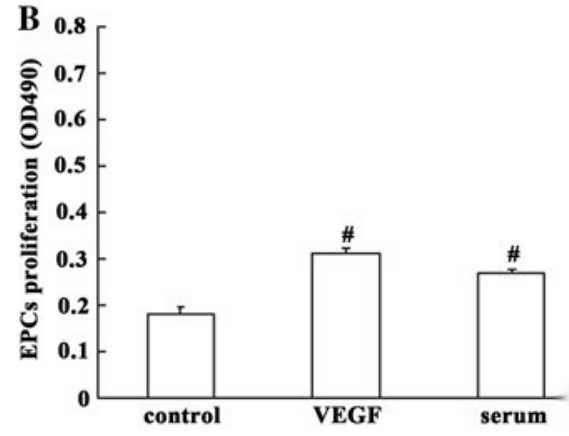

Fig. 2 Id1 expression is up-regulated in EPCs in the presence of VEGF. a Protein level of Id1 in the EPCs stimulated with serum and VEGF using western blot analysis. Values are presented as the percentage of GAPDH (serum and VEGF free, null treatment). b The proliferation of EPCs was examined by MTS assays. The proliferation

Id1 in quiescent EPCs was barely detectable, and it was dramatically increased in response to stimulations such as serum and VEGF, we therefore used siRNA fragments to silence the Id1 gene in EPCs, and the culture medium

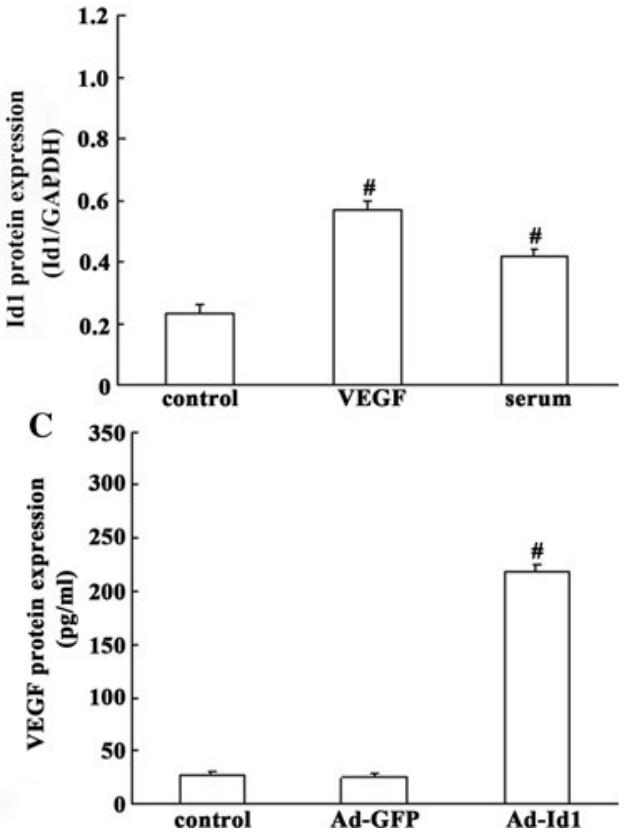

of EPCs was significantly accelerated after stimulation with VEGF compared with the control. c Supernatants from EPCs transfected with Ad-Id1 were collected and subjected to ELISA analysis, using VEGF specific kits. Expression of VEGF was increased by Ad-Id. The values are expressed as the mean $\pm \mathrm{SD} .{ }^{\sharp} P<0.05$ versus control

containing $20 \% \mathrm{FCS}$ and $10 \mathrm{ng} / \mathrm{ml}$ VEGF was used as stimulation. Instruction of si-Id1 caused an approximate $50 \%$ loss of Id1, p-PI3K, p-Akt, p-I $\kappa \mathrm{B}$, and survivin expression and decreased nuclear translocation of $\mathrm{NF} \kappa \mathrm{B} / \mathrm{p} 65$ 
Fig. 3 The influence of Id1 over-expression and silencing on the activation of the PI3K/ $\mathrm{Akt} / \mathrm{NF} \kappa \mathrm{B} /$ survivin signalling pathway and proliferation of EPCs. a, b Left proteins(Id1, p-PI3K, p-Akt, p-I $\kappa \mathrm{B}$, survivin, and nuclear $\mathrm{NF} \kappa \mathrm{B} / \mathrm{p} 65$ ) from EPCs transfected with Ad-Id1 or si-Id 1 were collected and subjected to western blot analysis. Right densitometric analysis of Id1, p-PI3K, p-Akt, $\mathrm{p}-\mathrm{I} \kappa \mathrm{B}, \mathrm{NF} \kappa \mathrm{B} / \mathrm{p} 65$ (nuclear), and survivin protein expression levels were determined by Quantity One. c, d The proliferation of EPCs was examined by MTS assays. The proliferation of EPCs transfected with Ad-Id1 was enhanced to about $200 \%$ as compared with that of Ad-GFPtransfected EPCs. Whereas knockdown of endogenous Id1 significantly reduced the proliferation of EPCs compared with the control group. The results are expressed as the mean $\pm \mathrm{SD} .{ }^{\#} P<0.05$ versus control

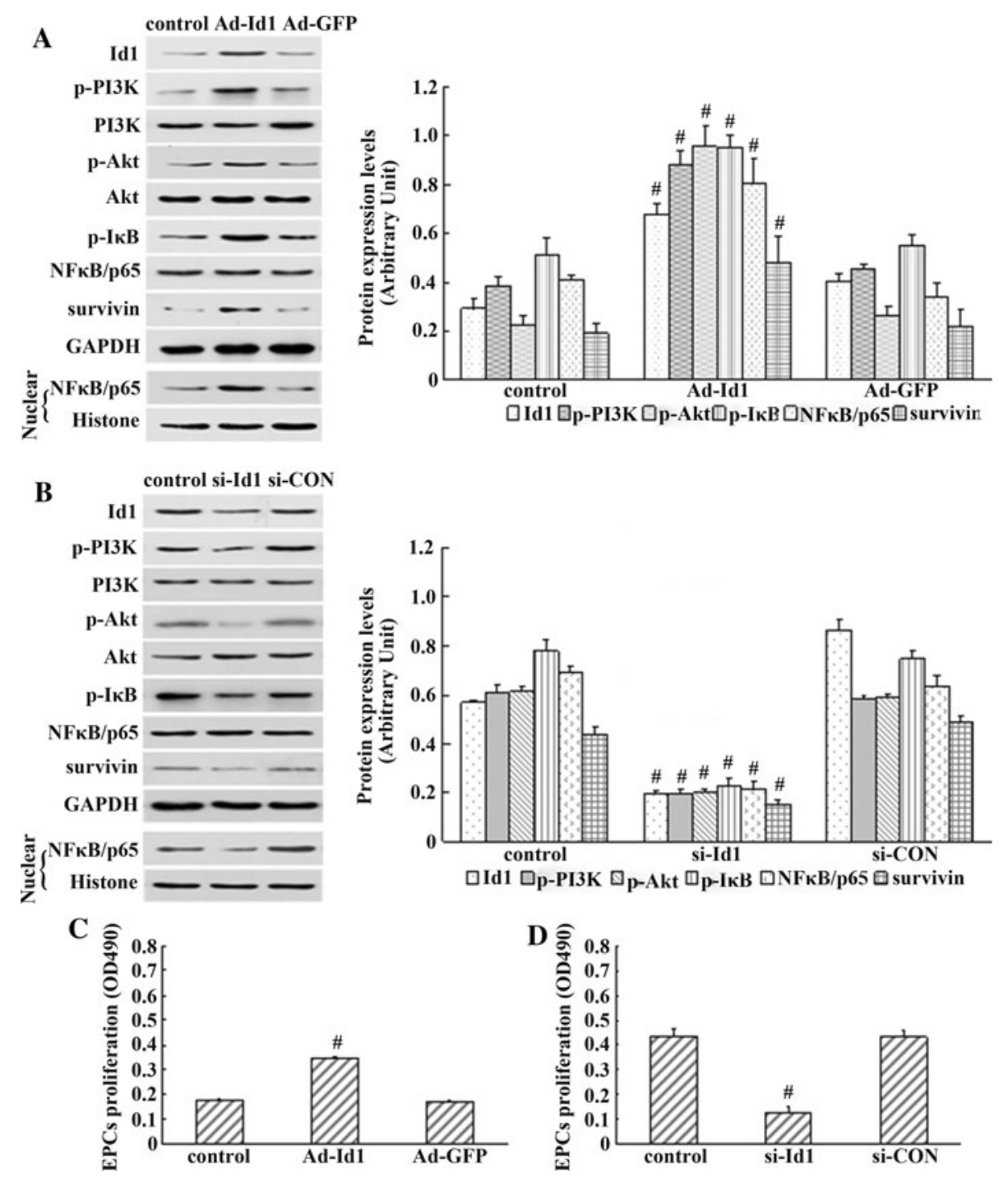

in EPCs as measured by western blot (Fig. 3b). And significantly, the EPCs exhibited a decrease in cell proliferation compared with the control group (Fig. 3d). Thus, these results indicated that knockdown of endogenous Id1 significantly reduced the proliferation of EPC, suggesting an important role in EPCs of endogenous Id1.

Taken together, our results indicated that Id1 activated the $\mathrm{PI} 3 \mathrm{~K} / \mathrm{Akt} / \mathrm{NF} \kappa \mathrm{B} / \mathrm{survivin}$ signalling pathway in the regulation of EPC proliferation.

PI3K blockade reduces Id1-induced $\mathrm{Akt} / \mathrm{NF} \kappa \mathrm{B} /$ survivin activation

It has been documented that Id1 activates Akt through the PI3K pathway. To investigate the role of PI3K in Id1induced EPC proliferation and determine whether PI3K is involved in the induction of $\mathrm{Akt} / \mathrm{NF} \kappa \mathrm{B} /$ survivin in the Id1over-expressing EPCs, cells transfected with Ad-Id1 were incubated with a PI3K-specific inhibitor, LY294002. The
MTS assay and western blot analysis were performed at $48 \mathrm{~h}$ after transfection. As shown in Fig. $4 \mathrm{a}$, treatment with LY294002 attenuated Id1-induced p-PI3K, p-Akt, p-I $\kappa$ B, and survivin expression as well as decreased the nuclear translocation of $\mathrm{NF} \kappa \mathrm{B} / \mathrm{p} 65$ in EPCs transfected with Ad-Id1. This result indicated the significance of PI3K in the activation of the $\mathrm{Akt} / \mathrm{NF} \kappa \mathrm{B} /$ survivin pathway. The proliferation effect was strongly inhibited by the PI3K-specific inhibitor LY294002 compared with the proliferation in untreated Ad-Id1-transfected EPCs (Fig. 4b). These data suggested that the effect of PI3K inhibition on Id1-induced EPC proliferation may be due to reduced $\mathrm{Akt} / \mathrm{NF} \kappa \mathrm{B} /$ survivin activity.

Id1-induced nuclear translocation of $\mathrm{NF} \kappa \mathrm{B} / \mathrm{p} 65$ is mediated through PI3K/Akt signalling

$\mathrm{NF} \kappa \mathrm{B}$ is a ubiquitously expressed transcription factor that has been reported to be downstream of the PI3K/Akt pathway. After finding that Id1 activated PI3K, Akt, and 

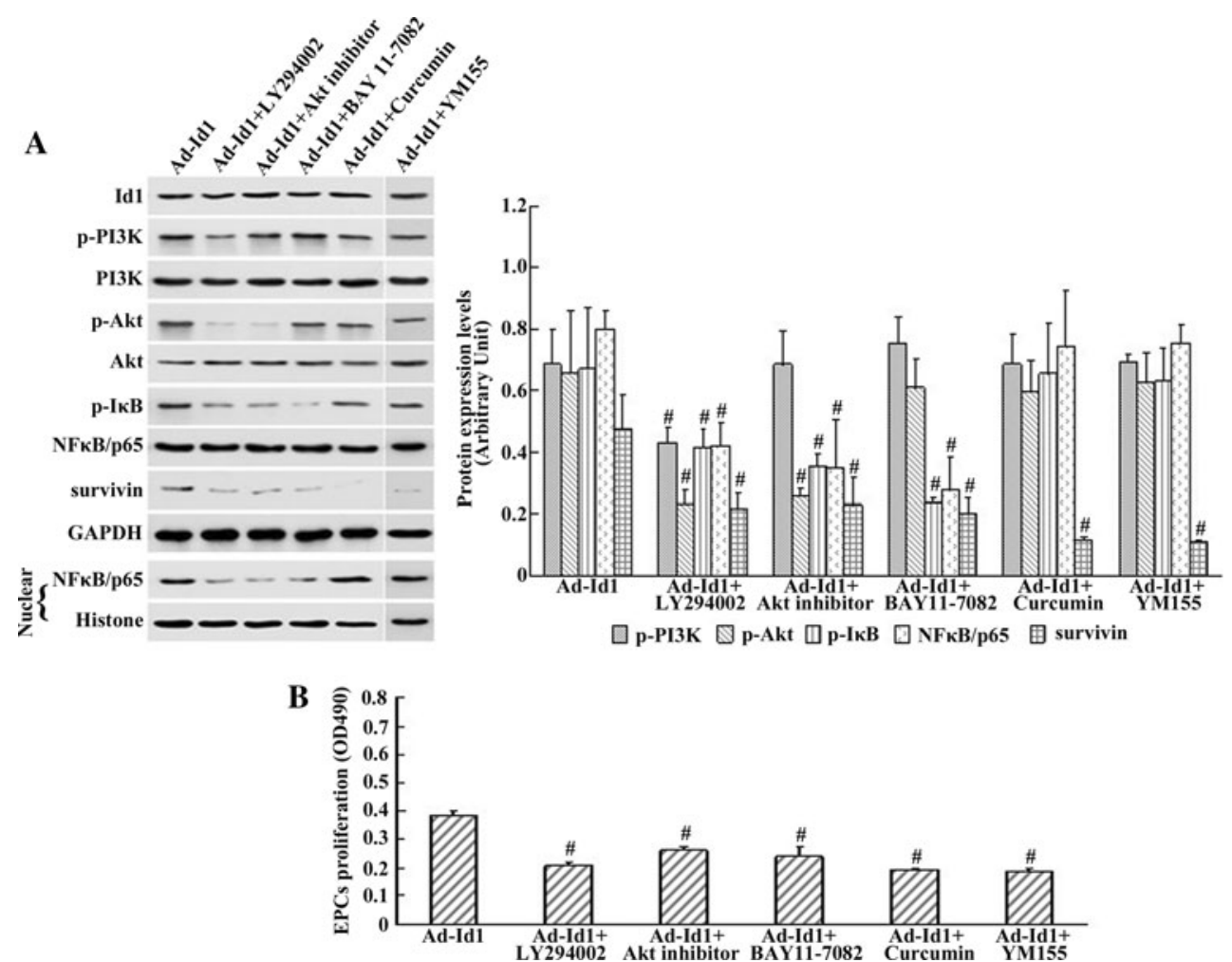

Fig. 4 Blockage of the PI3K/Akt/NF $\kappa \mathrm{B} /$ survivin signalling pathway abrogated Id1-induced EPC proliferation. a Left western blot demonstrating that blockade by the PI3K-specific inhibitor LY294002 and Akt inhibitor reduced p-Akt, p-I $\kappa \mathrm{B}$, survivin expression, and $\mathrm{NF} \kappa \mathrm{B} /$ p65 nuclear translocation in EPCs transfected with Ad-Id1. Treatment with the NF $\kappa \mathrm{B}$ inhibitor BAY 11-7082 significantly decreased the nuclear translocation of $\mathrm{NF} \kappa \mathrm{B}$ subunit $\mathrm{p} 65$ but did not affect PI3K/ Akt activity. Treatment with the survivin inhibitor Curcumin or YM155 significantly decreased the expression of survivin but did not affect $\mathrm{PI} 3 \mathrm{~K} / \mathrm{Akt} / \mathrm{NF} \kappa \mathrm{B}$ activity. Right densitometric analysis of Id1, $\mathrm{p}-\mathrm{PI} 3 \mathrm{~K}, \mathrm{p}-\mathrm{Akt}, \mathrm{p}-\mathrm{I} \kappa \mathrm{B}, \mathrm{NF} \kappa \mathrm{B} / \mathrm{p} 65$ (nuclear), and survivin protein expression levels were determined by Quantity One. b The proliferation of EPCs was examined by MTS assays. The proliferation of EPCs was enhanced in the presence of Ad-Id1. The effect was damped in the presence of the PI3K-specific inhibitor LY294002, Akt inhibitor, the $\mathrm{NF} \kappa \mathrm{B}$ inhibitor BAY 11-7082, the survivin inhibitor Curcumin, or the survivin inhibitor YM155. The values are expressed as the mean $\pm \mathrm{SD} .{ }^{\#} P<0.05$ versus Ad-Id1
$\mathrm{NF} \kappa \mathrm{B}$, we wished to demonstrate that PI3K/Akt is required for the Id1-mediated activation of $N F \kappa B$. After incubation with an Akt-specific inhibitor, we measured the nuclear translocation of $\mathrm{NF} \kappa \mathrm{B} / \mathrm{p} 65$ and survivin expression in cells transfected with Ad-Id1 using western blot analysis. As shown in Fig. 4a, inhibition of Akt activity in Ad-Id1transfected EPCs by Akt inhibitor reduced the expression of $\mathrm{p}-\mathrm{Akt}, \mathrm{p}-\mathrm{I} \kappa \mathrm{B}$, and survivin as well as decreased the nuclear translocation of $\mathrm{NF} \kappa \mathrm{B} / \mathrm{p} 65$. Cell proliferation measured by the MTS assay in the Akt-specific inhibitor group was significantly lower than that in the Ad-Id1 group (Fig. 4b). These results suggested that $\mathrm{NF} \kappa \mathrm{B}$ activation was mediated through the PI3K/Akt signalling pathway.

$\mathrm{NF} \kappa \mathrm{B}$ inhibition can reduce Id-induced survivin activation

Because $\mathrm{NF} \kappa \mathrm{B}$ and survivin are co-expressed in many types of cancer cells that are induced to proliferate by Id1, we postulated that Id1 might control the expression of survivin in EPCs via NF $\kappa \mathrm{B}$. To test this hypothesis, EPCs transfected with Ad-Id1 were treated with the $\mathrm{NF} \kappa \mathrm{B}$ inhibitor BAY 11-7082, which resulted in attenuated phosphorylation of $\mathrm{I} \kappa \mathrm{B}$ and nuclear translocation of $\mathrm{NF} \kappa \mathrm{B} /$ p65 without effects on PI3K/Akt activity (Fig. 4a). Simultaneously, Id1-induced survivin expression was abrogated by BAY 11-7082 as judged by western blot analysis (Fig. 4a). Interestingly, treatment with the $\mathrm{NF} \kappa \mathrm{B}$ inhibitor decreased the proliferation of EPCs compared with the proliferation of EPCs transfected with Ad-Id1 (Fig. 4b). These results suggested that survivin may be a downstream effector molecule of $\mathrm{NF} \kappa \mathrm{B}$ that could mediate this process.

Survivin inhibition impairs Id1-induced EPC proliferation

To determine whether survivin had an effect on EPC proliferation, rat spleen-derived EPCs were cultured for in vitro experiments. The survivin inhibitor Curcumin and 
YM155 was separately added to EPCs transfected with Ad-Id. The basal and induced survivin levels were detected in vitro by western blot analysis. Interestingly, treatment with the survivin inhibitor Curcumin and YM155 significantly decreased the expression of survivin but did not affect PI3K/Akt/NF $\kappa$ B activity (Fig. 4a). Concomitantly, the inhibition of survivin by Curcumin and YM155 significantly suppressed the proliferation of EPCs (Fig. 4b). These results demonstrated that survivin might be an important effector molecule that could promote EPC proliferation in vitro.

The effect of PI3K/Akt inhibition on the expression of Id1 in EPCs

In the present study, we observed that Id1 activated the PI3K/Akt signalling pathway in the regulation of EPC proliferation. In addition, observations from others showed that inhibition of PI3K/Akt down-regulated the expression level of Id 1 and reduced EPCs functions [23]. Therefore, we concluded that there is an interaction between Id1 and PI3K/Akt signalling pathway in EPCs. To test this hypothesis, EPCs transfected and not transfected with AdId1 were separately incubated with PI3K/Akt signalling inhibitor LY294002. As shown in Fig. 5a, Id1 and p-Akt expression were strongly decreased by LY294002 in EPCs without exogenous Id1 transfection. However, inhibition of PI3K/Akt activity in Ad-Id1-transfected EPCs by LY294002 reduced the expression of p-Akt only but not Id1 (Fig. 5b). These results indicated that there was an important interaction between PI3K/Akt and endogenous Id1 in EPCs, which might ensemble contribute to the EPC proliferation.
Impact of Id1 on the effects of CCN1 and p21

Recent studies have indicated that Id1 expression is involved in the expression of CCN1, and p21, thereby regulating EPC proliferation and the re-endothelialisation $[19,27]$. To investigate the role of CCN1, and $\mathrm{p} 21$, in Id1induced EPC proliferation and determine whether Id1 is involved in the expression of CCN1, and p21, in EPCs, the MTS assay and western blot analysis were performed. As shown in Fig. 6a, a 50\% decrease in protein level of Id1 was detected in response to Ad-CCN1. Interestingly, cotransfection with Ad-CCN1 decreased the proliferation of EPCs compared with the proliferation of EPCs transfected with Ad-Id1 (Fig. 6b). These data showed that, potently, CCN1 mediated the effect of Id1 on EPC proliferation, but the exact mechanism remains to be fully understood. In order to clarify whether Id1 is involved in the expression of p21, Ad-Id1 and si-Id1 were performed. As shown in Fig. 6c, there was decreased p21 expression in EPCs transfected with Ad-Id1, and instruction of si-Id1 extensively improved p21 expression by western blot (Fig. 6d). Taken together, these results demonstrated that Id 1 expression was involved in the expression of CCN1, and p21, thereby regulating EPC proliferation in vitro.

\section{Discussion}

Our present results demonstrated that Id1 stimulated cell proliferation; up-regulated p-PI3K, p-Akt, p-I $\kappa \mathrm{B}$, and survivin expression; and promoted the nuclear translocation of $\mathrm{NF} \kappa \mathrm{B} / \mathrm{p} 65$ in EPCs. These effects were abrogated in the presence of the PI3K-specific inhibitor LY294002, the Akt
Fig. 5 The effects of PI3K/Akt inhibition on the expression of Id 1 in EPCs. a Id 1 and p-Akt were strongly decreased by $\mathrm{PI} 3 \mathrm{~K} / \mathrm{Akt}$ signalling inhibitor LY294002 in EPCs without exogenous Id 1 transfection. The values are expressed as the mean $\pm \mathrm{SD} .{ }^{\#} P<0.05$ versus control. b Inhibition of PI3K/ Akt activity in Ad-Id1transfected EPCs by LY294002 reduced the expression of $\mathrm{p}$-Akt only but not Id1. The results are expressed as the mean $\pm \mathrm{SD}$. ${ }^{\#} P<0.05$ versus Ad-Id 1

\section{A}
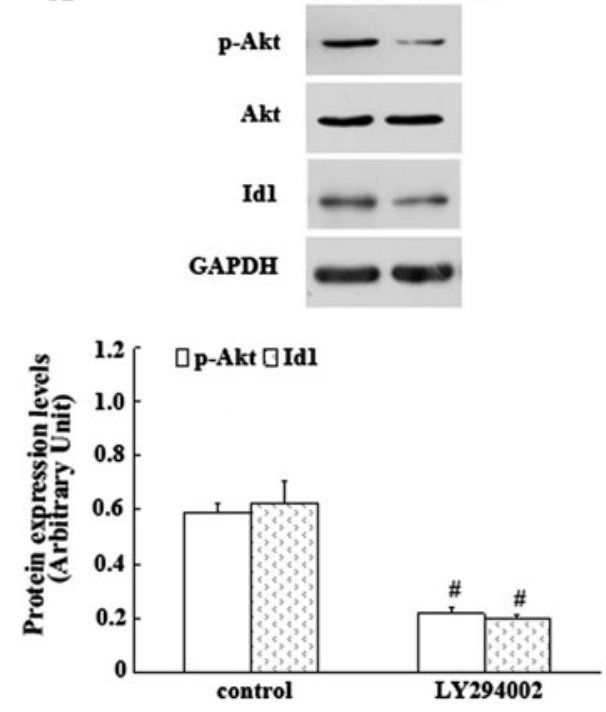

B
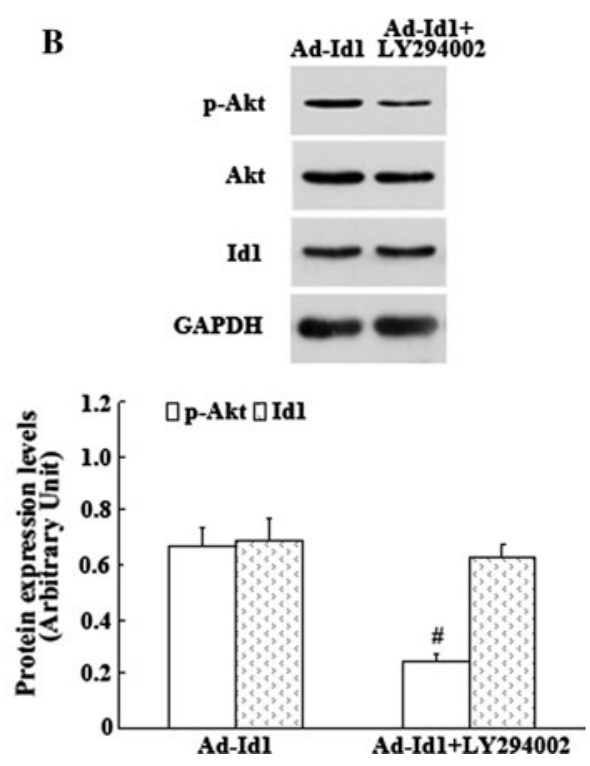
Fig. 6 Impact of Id1 on the effects of CCN1, and p21. a Id1 expression in EPCs was downregulated by Ad-CCN1. The values are expressed as the mean $\pm \mathrm{SD} .{ }^{\#} P<0.05$ versus control. b Cotransfection with Ad-CCN1 decreased the proliferation of EPCs. The results are expressed as the mean \pm SD. ${ }^{\#} P<0.05$ versus Ad-GFP; $* P<0.05$ versus AdId1. c, $\mathbf{d}$ The expression of $\mathrm{p} 21$ was decreased by overexpression of Ad-mediated exogenous Id 1 and improved by silencing of endogenous Id 1 in EPCs. The values are expressed as the mean \pm SD. ${ }^{\#} P<0.05$ versus control

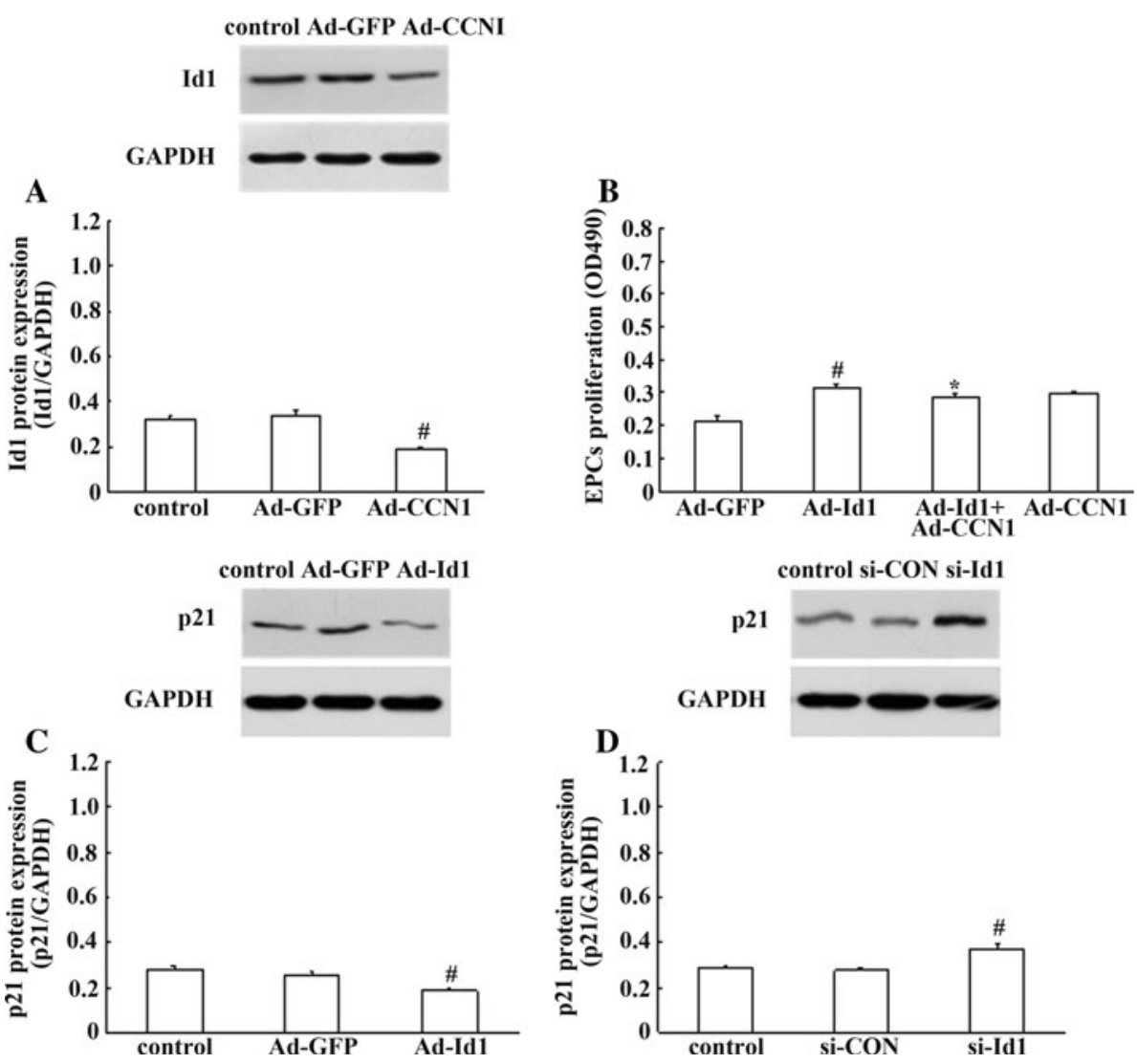

inhibitor, the NF $\kappa$ B inhibitor BAY 11-7082, the survivin inhibitor Curcumin, and the survivin inhibitor YM155. Simultaneously, knockdown of endogenous Id1 significantly reduced the proliferation of EPCs, and led to suppression of $\mathrm{PI} 3 \mathrm{~K} / \mathrm{Akt} / \mathrm{NF} \kappa \mathrm{B} /$ survivin signalling pathway in EPCs. These results demonstrated that the proliferation of EPCs is mediated through the Id1/PI3K/Akt/NF $\kappa \mathrm{B} /$ survivin signalling pathway.

Id1 is an important subfamily member of the HLH transcriptional factor family. Id1 proteins are essential for cell cycle progression in some cell lines, acting as positive regulators of cell proliferation. Recent studies demonstrated that Id1 plays an important role in the regulation of cell proliferation and survival in human cancers [17, 28]. In a previous study, we also identified that Id1 has a critical role in regulating the proliferation of EPCs [18]. Here, we showed that Id1 was present at a fairly low level in quiescent EPCs, but was rapidly up-regulated upon stimulation with VEGF. The proliferation of EPCs was extensively improved after stimulation with VEGF. However, the mechanism responsible for Id1 signalling pathway activation in EPCs is largely unknown. The prolific function of Id1 may involve multiple signalling pathways. First, proangiogenic surface proteins such as $\beta 4$ integrin fibroblast growth factor receptor-1, and metalloprotease-2, which were attributed to the proliferation of EPCs during re-endothelialisation after vascular injury, have been suggested to be downstream molecules of Id1 [18, 23]. Second, the growth-promoting function of Id1 also involves the activation of the mitogen-activated protein kinase and mouse double minute- 2 signalling pathway in many types of cancer cells [17, 28, 29]. Third, studies have reported that the SDF1 receptor CXCR4 is regulated by Id1 in T cells, and the SDF1/CXCR4 interaction plays an important role in the regulation of EPC proliferation [30].

Recent studies have indicated that Id1 is linked to the survival of many types of human cancers via its regulation of the PI3K/Akt, PI3K/Akt/NF $\kappa \mathrm{B}$, and $\mathrm{NF} \kappa \mathrm{B} /$ survivin signalling pathways following the initial effects on cellular proliferation [20-22, 31]. The transfection of head and neck squamous cell carcinoma cells with Id1 in vitro induced the phosphorylation of Akt (p-Akt) via PI3K and increased the expression of survivin via $\mathrm{NF} \kappa \mathrm{B}$. Additionally, inhibiting Id1 expression in many types of cells using short interfering RNA (siRNA) significantly reduced PI3K/ Akt and $\mathrm{NF} \kappa \mathrm{B}$ signalling pathways expression. However, the mechanism responsible for Id1/PI3K/Akt/NF $\kappa \mathrm{B} /$ survivin activation in EPCs is incompletely understood.

Pertaining to the recent studies, there are many similarities and differences between EPCs and cancer cells with regard to the Id1/PI3K/Akt/NF $\kappa \mathrm{B} /$ survivin signalling pathway. It is documented that the Id1/PI3K/Akt, 
$\mathrm{PI} 3 \mathrm{~K} / \mathrm{Akt} / \mathrm{NF} \kappa \mathrm{B}$, and $\mathrm{NF} \kappa \mathrm{B} /$ survivin signalling pathways play important regulations both in EPCs and in cancer cells proliferation [20, 22, 32, 33]. However, Id1, PI3K/Akt, $\mathrm{NF} \kappa \mathrm{B}$, and survivin are potentially up-regulated in a wide variety of human cancer cells compared with normal EPCs. Id1, PI3K/Akt, $\mathrm{NF} \kappa \mathrm{B}$, and survivin may be candidate genes for cellular survival of several types of cancer cells, and the Id1/PI3K/Akt, PI3K/Akt/NF $\kappa \mathrm{B}$, and $\mathrm{NF} \kappa \mathrm{B} /$ survivin signalling pathways are involved in many types of cancer cells apoptosis resistance and survival [21]. Unlike cancer cells or tissues, the basal expression of Id1, PI3K/ Akt, $\mathrm{NF} \kappa \mathrm{B}$, and survivin in quiescent EPCs was barely detectable. Our previous studies demonstrated that overexpression of exogenous Id1 directly stimulated proliferation and migration of EPCs [18]. Additionally, the PI3K/ Akt and $\mathrm{PI} 3 \mathrm{~K} / \mathrm{Akt} / \mathrm{NF} \kappa \mathrm{B}$ signalling pathways play a pivotal role in the process of EPC mobilisation [32, 34], migration, homing, and angiogenesis. But the relationship between Id1, PI3K/Akt, and NF $\kappa \mathrm{B} /$ survivin in the biological function of EPCs is largely unknown at present. Therefore, further studies will be required to determine whether the Id1/PI3K/Akt/NF $\kappa \mathrm{B} /$ survivin signalling pathway is involved in regulating the biological functions of EPCs.

In this study, we determined the effects of Id1/PI3K/ $\mathrm{Akt} / \mathrm{NF} \kappa \mathrm{B} /$ survivin signalling on EPC proliferation using western blot analysis and MTS assays. The present results identified that Id1 induced the activation of the PI3K/Akt/ $\mathrm{NF} \kappa \mathrm{B} /$ survivin signalling pathway during EPC proliferation. The in vitro transfection of EPCs with Ad-Id1 induced the phosphorylation of Akt via PI3K and increased the expression of survivin via $\mathrm{NF} \kappa \mathrm{B}$. Simultaneously, knockdown of endogenous Id1 significantly reduced the proliferation of EPCs, and led to suppression of PI3K/Akt/ $\mathrm{NF} \kappa \mathrm{B} /$ survivin signalling pathway in EPCs. Therefore, these evidences suggest that the prolific property of EPCs is attributable to the up-regulation of Id1, p-PI3K, p-Akt, and survivin, as well as the nuclear translocation of $\mathrm{NF} \kappa \mathrm{B} /$ p65. In addition, blockage of the PI3K/Akt/NF $\kappa \mathrm{B} /$ survivin signalling pathway by the PI3K inhibitor LY294002, the Akt-specific inhibitor, the $\mathrm{NF} \kappa \mathrm{B}$ inhibitor BAY 11-7082, the survivin inhibitor Curcumin, and the survivin inhibitor YM155 abrogated Id1-induced EPC proliferation. Interestingly, treatment with the NF $\kappa$ B inhibitor BAY 11-7082 significantly decreased the nuclear translocation of $\mathrm{NF} \kappa \mathrm{B}$ subunit p65 but did not affect PI3K/Akt activity. This indicates that PI3K/Akt is upstream of NF $\kappa \mathrm{B}$. Treatment with the survivin inhibitor Curcumin or YM155 significantly decreased the expression of survivin but did not affect $\mathrm{PI} 3 \mathrm{~K} / \mathrm{Akt} / \mathrm{NF} \kappa \mathrm{B}$ activity. This finding indicates that survivin is downstream of $\mathrm{PI} 3 \mathrm{~K} / \mathrm{Akt} / \mathrm{NF} \kappa \mathrm{B}$. These findings, taken together, demonstrate the existence of an Id1/
$\mathrm{PI} 3 \mathrm{~K} / \mathrm{Akt} / \mathrm{NF} \kappa \mathrm{B} /$ survivin signalling pathway during $\mathrm{EPC}$ proliferation.

In this study, we explored the effect of PI3K/Akt inhibition on the Id1 expression in EPCs. Little is known about the interaction between PI3K/Akt and Id1 in EPC proliferation. We demonstrated that over-expression of exogenous Id1 directly stimulated up-regulation of $\mathrm{p}-\mathrm{PI} 3 \mathrm{~K}$ and p-Akt and proliferation of EPCs. In this study, we showed that Id1 and p-Akt were strongly decreased by PI3K/Akt signalling inhibitor LY294002 in EPCs without exogenous Id1 transfection. Interestingly, inhibition of PI3K/Akt activity in Ad-Id1-transfected EPCs by LY294002 reduced the expression of p-Akt only but not Id1. This is a novel finding. Taken together, our data support the notion that there is an important interaction between PI3K/Akt and endogenous Id1 in EPCs, which might ensemble contribute to the EPC proliferation.

Furthermore, we investigated whether Id1 is involved in the expression of VEGF, CCN1, and p21 in EPCs. Several reports revealed that Id1 is involved in the expression of VEGF, p21, and CCN1, thereby regulating EPC proliferation and the re-endothelialisation [17, 19, 27, 35]. Our study observed that transfection of Ad-Id1 into EPCs increased the release of VEGF. It was intriguing to observe such effect of Id, as VEGF are thought to be important mediators of EPCs proliferation. However, Id1 was induced by VEGF, which has been proven by our study. In this study, our results showed that VEGF up-regulated Id1 in EPCs, and vice versa, strengthening the hypothesis that a paracrine loop may exist between Id1 and VEGF that regulates EPC proliferation. In this study, we found that Id1 expression in EPCs was down-regulated by Ad-CCN1, which is in accordance with our previous studies [27]. In addition, cotransfection with Ad-CCN1 decreased the proliferation of EPCs. To date, the exact interaction between $\mathrm{CCN} 1$ and Id1 in EPC proliferation remains elusive and further studies are needed to make it clear. Previous studies have revealed that the restraint of p21 expression by Id1 is one key element of its activity in facilitating the generation of EPCs [19]. Our present results demonstrated that the expression of p21 was decreased by over-expression of Ad-mediated exogenous Id1 and improved by silencing of endogenous Id1 in EPCs. Taken together, these results demonstrated that Id1 expression is involved in the expression of VEGF, CCN1, and p21, thereby regulating EPC proliferation in vitro.

However, this study has many limitations as follows: (1) our observations were based on an in vitro experiment and not an animal model of vascular injury, and thus, the conclusions drawn may be limited to cell experiments; (2) thus far, we do not know whether the up-regulation of survivin can cause carcinoma in an animal model, and 
the observation related to survivin was limited to in vitro experiments.

In summary, we demonstrated that Id1 is a critical regulator of EPC proliferation, and the Id1/PI3K/Akt/ $\mathrm{NF} \kappa \mathrm{B} /$ survivin signalling pathway may play an important role during EPC proliferation. Id1, PI3K, Akt, $\mathrm{NF} \kappa \mathrm{B}$, and survivin may represent novel therapeutic targets for re-endothelialisation after vascular injury.

Acknowledgements We thank Meng-yang Deng and Hua-li Kang for excellent technical help. This study was supported in part by the National Natural Science Foundation of China (Grant 30770852 and 81000070).

Open Access This article is distributed under the terms of the Creative Commons Attribution Noncommercial License which permits any noncommercial use, distribution, and reproduction in any medium, provided the original author(s) and source are credited.

\section{References}

1. Calvet D, Touze E, Varenne O, Sablayrolles JL, Weber S, Mas JL (2010) Prevalence of asymptomatic coronary artery disease in ischemic stroke patients: the PRECORIS study. Circulation 121: 1623-1629

2. Ong AT, McFadden EP, Regar E, de Jaegere PP, van Domburg RT, Serruys PW (2005) Late angiographic stent thrombosis (LAST) events with drug-eluting stents. J Am Coll Cardiol 45:2088-2092

3. Zhu SK, Malhotra A, Zhang LS, Deng SM, Zhang TF, Freedman NJ, Storms R, Peppel K, Goldschmidt-Clermont PJ, Dong CM (2010) Human umbilical cord blood endothelial progenitor cells decrease vein graft neointimal hyperplasia in SCID mice. Atherosclerosis 212:63-69

4. Tran TC, Kimura K, Nagano M, Yamashita T, Ohneda K, Sugimori H, Sato F, Sakakibara Y, Hamada H, Yoshikawa H, Hoang SN, Ohneda O (2011) Identification of human placentaderived mesenchymal stem cells involved in re-endothelialization. J Cell Physiol 226:224-235

5. Zhu GX, Huang L, Song MB, Yu ZP, Wu XJ, Zhao XH, Jin J, Zhao G, Chen JF, Yu SY (2010) Over-expression of hepatocyte growth factor in smooth muscle cells regulates endothelial progenitor cells differentiation, migration and proliferation. Int $\mathbf{J}$ Cardiol 138:70-80

6. Hristov M, Weber C (2004) Endothelial progenitor cells: characterization, pathophysiology, and possible clinical relevance. J Cell Mol Med 8:498-508

7. Pearson JD (2009) Endothelial progenitor cells-hype or hope? J Thromb Haemost 7:255-262

8. Caporali A, Pani E, Horrevoets AJ, Kraenkel N, Oikawa A, SalaNewby GB, Meloni M, Cristofaro B, Graiani G, Leroyer AS, Boulanger CM, Spinetti G, Yoon SO, Madeddu P, Emanueli C (2008) Neurotrophin p75 receptor (p75NTR) promotes endothelial cell apoptosis and inhibits angiogenesis: implications for diabetes-induced impaired neovascularization in ischemic limb muscles. Circ Res 103:e15-e26

9. Garg R, Tellez A, Alviar C, Granada J, Kleiman NS, Lev EI (2008) The effect of percutaneous coronary intervention on inflammatory response and endothelial progenitor cell recruitment. Catheter Cardiovasc Interv 72:205-209

10. Dzau VJ, Gnecchi M, Pachori AS, Morello F, Melo LG (2005) Therapeutic potential of endothelial progenitor cells in cardiovascular diseases. Hypertension 46:7-18
11. Miller-Kasprzak E, Jagodzinski PP (2007) Endothelial progenitor cells as a new agent contributing to vascular repair. Arch Immunol Ther Exp (Warsz) 55:247-259

12. Tanaka K, Sata M, Natori T, Kim-Kaneyama J, Nose K, Shibanuma M, Hirata Y, Nagai R (2008) Circulating progenitor cells contribute to neointimal formation in nonirradiated chimeric mice. FASEB J 22:428-436

13. Hibbert B, Ma XL, Pourdjabbar A, Holm E, Rayner K, Chen YX, Sun JF, Filion L, O'Brien ER (2009) Inhibition of endothelial progenitor cell glycogen synthase kinase-3b results in attenuated neointima formation and enhanced re-endothelialization after arterial injury. Cardiovasc Res 83:16-23

14. Lin HH, Chen YH, Yet SF, Chau LY (2009) After vascular injury, heme oxygenase-1/carbon monoxide enhances re-endothelialization via promoting mobilization of circulating endothelial progenitor cells. J Thromb Haemost 7:1401-1408

15. Kuang CY, Yu Y, Guo RW, Qian DH, Wang K, Den MY, Shi YK, Huang L (2010) Silencing stromal interaction molecule 1 by RNA interference inhibits the proliferation and migration of endothelial progenitor cells. Biochem Biophys Res Commun 398:315-320

16. Mellick AS, Plummer PN, Nolan DJ, Gao D, Bambino K, Hahn M, Catena R, Turner V, McDonnell K, Benezra R, Brink R, Swarbrick A, Mittal V (2010) Using the transcription factor inhibitor of DNA binding 1 to selectively target endothelial progenitor cells offers novel strategies to inhibit tumor angiogenesis and growth. Cancer Res 70:7273-7282

17. Hui CM, Cheung PY, Ling MT, Tsao SW, Wang X, Wong YC, Cheung AL (2006) Id-1 promotes proliferation of p53-deficient esophageal cancer cells. Int J Cancer 119:508-514

18. Huang L, Wang H, Yu Y, Guo RW, Shi YK, Song MB, Chen JF, Yu SY, Yin YG, Gao P (2010) Inhibitor of DNA binding-1 promotes the migration and proliferation of endothelial progenitor cells in vitro. Mol Cell Biochem 335:19-27

19. Ciarrocchi A, Jankovic V, Shaked Y, Nolan DJ, Mittal V, Kerbel RS, Nimer SD, Benezra R (2007) Id1 restrains p21 expression to control endothelial progenitor cell formation. PLoS One 2: e1338

20. Li B, Cheung PY, Wang X, Tsao SW, Ling MT, Wong YC, Cheung AL (2007) Id-1 activation of PI3K/Akt/NFkappaB signaling pathway and its significance in promoting survival of esophageal cancer cells. Carcinogenesis 28:2313-2320

21. Li B, Tsao SW, Li YY, Wang X, Ling MT, Wong YC, He QY, Cheung AL (2009) Id-1 promotes tumorigenicity and metastasis of human esophageal cancer cells through activation of PI3K/ AKT signaling pathway. Int J Cancer 125:2576-2585

22. Lin J, Guan Z, Wang C, Feng L, Zheng Y, Caicedo E, Bearth E, Peng JR, Gaffney P, Ondrey FG (2010) Inhibitor of differentiation 1 contributes to head and neck squamous cell carcinoma survival via the NF-kappaB/survivin and phosphoinositide 3-kinase/Akt signaling pathways. Clin Cancer Res 16:77-87

23. Su Y, Zheng L, Wang Q, Bao J, Cai Z, Liu A (2010) The PI3K/ Akt pathway upregulates Id1 and integrin alpha4 to enhance recruitment of human ovarian cancer endothelial progenitor cells. BMC Cancer 10:459

24. Su JC, Lin KL, Chien CM, Tseng CH, Chen YL, Chang LS, Lin SR (2010) Naphtho[1,2-b]furan-4,5-dione inactivates EGFR and PI3K/Akt signaling pathways in human lung adenocarcinoma A549 cells. Life Sci 86:207-213

25. Kanwar JR, Kamalapuram SK, Kanwar RK (2011) Targeting survivin in cancer: the cell-signalling perspective. Drug Discov Today 16:485-494

26. Zhao X, Huang L, Yin Y, Fang Y, Zhao J, Chen J (2008) Estrogen induces endothelial progenitor cells proliferation and migration by estrogen receptors and PI3K-dependent pathways. Microvasc Res 75:45-52 
27. Yu Y, Gao Y, Qin J, Kuang CY, Song MB, Yu SY, Cui B, Chen JF, Huang L (2010) CCN1 promotes the differentiation of endothelial progenitor cells and reendothelialization in the early phase after vascular injury. Basic Res Cardiol 105:713-724

28. Cheung HW, Ling MT, Tsao SW, Wong YC, Wang X (2004) Id1-induced Raf/MEK pathway activation is essential for its protective role against taxol-induced apoptosis in nasopharyngeal carcinoma cells. Carcinogenesis 25:881-887

29. Di K, Wong YC, Wang X (2007) Id-1 promotes TGF-beta1induced cell motility through HSP27 activation and disassembly of adherens junction in prostate epithelial cells. Exp Cell Res 313:3983-3999

30. Sikder H, Huso DL, Zhang H, Wang B, Ryu B, Hwang ST, Powell JD, Alani RM (2003) Disruption of Id1 reveals major differences in angiogenesis between transplanted and autochthonous tumors. Cancer Cell 4:291-299

31. Koul D, Takada Y, Shen R, Aggarwal BB, Yung WK (2006) PTEN enhances TNF-induced apoptosis through modulation of nuclear factor-kappaB signaling pathway in human glioma cells. Biochem Biophys Res Commun 350:463-471
32. Wang YY, Yan W, Lu XM, Qian CF, Zhang JX, Li P, Shi L, Zhao P, Fu Z, Pu PY, Kang CS, Jiang T, Liu N, You YP (2011) Overexpression of osteopontin induces angiogenesis of endothelial progenitor cells via the av beta 3/PI3K/AKT/eNOS/NO signaling pathway in glioma cells. Eur J Cell Biol 90:642-648

33. Honda A, Matsuura K, Fukushima N, Tsurumi Y, Kasanuki H, Hagiwara N (2009) Telmisartan induces proliferation of human endothelial progenitor cells via PPAR gamma-dependent PI3K/ Akt pathway. Atherosclerosis 205:376-384

34. Lev EI, Leshem-Lev D, Mager A, Vaknin-Assa H, Harel N, Zimra Y, Bental T, Greenberg G, Dvir D, Solodky A, Assali A, Battler A, Kornowski R (2010) Circulating endothelial progenitor cell levels and function in patients who experienced late coronary stent thrombosis. Eur Heart J 31:2625-2632

35. Wang G, Qiu J, Hu J, Tang C, Yin T (2011) Id1: a novel therapeutic target for patients with atherosclerotic plaque rupture. Med Hypotheses 76:627-628 